\title{
Surface tension and wetting properties of rapeseed oil to biofuel conversion by-products
}

\author{
Siemowit Muszyński ${ }^{1 *}$, Agnieszka Sujak ${ }^{1}$, Andrzej Stęniewski ${ }^{1}$, Krzysztof Kornarzyński ${ }^{1}$, Marta Ejtel ${ }^{1}$, \\ Natalia Kowal ${ }^{1}$ Agnieszka Tomczyk-Warunek ${ }^{2}$,Emil Szcześniak', Marta Tomczyńska-Mleko ${ }^{3}$, \\ and Stanistaw Mleko ${ }^{4}$ \\ ${ }^{1}$ Department of Physics, University of Life Sciences in Lublin, Akademicka 13, \\ ${ }^{2}$ Department of Animal Physiology, University of Life Sciences in Lublin, Akademicka 12, \\ ${ }^{3}$ Institute of Plant Genetics, Breeding and Biotechnology, University of Life Sciences in Lublin, Akademicka 15; \\ 20-950 Lublin, Poland \\ ${ }^{4}$ Department of Milk Technology and Hydrocolloids, University of Life Sciences in Lublin, Skromna 8, 20-704 Lublin, Poland
}

Received September 13, 2017; accepted January 31, 2018

\begin{abstract}
This work presents a study on the surface tension, density and wetting behaviour of distilled glycerol, technical grade glycerol and the matter organic non-glycerin fraction. The research was conducted to expand the knowledge about the physical properties of wastes from the rapeseed oil biofuel production. The results show that the densities of technical grade glycerol $\left(1.300 \mathrm{~g} \mathrm{~cm}^{-3}\right)$ and distilled glycerol $\left(1.267 \mathrm{~g} \mathrm{~cm}^{-3}\right)$ did not differ and were significantly lower than the density of the matter organic non-glycerin fraction $\left(1.579 \mathrm{~g} \mathrm{~cm}^{-3}\right)$. Furthermore, the surface tension of distilled glycerol $\left(49.6 \mathrm{mN} \mathrm{m}^{-1}\right)$ was significantly higher than the matter organic non-glycerin fraction $\left(32.7 \mathrm{mN} \mathrm{m}^{-1}\right)$ and technical grade glycerol $\left(29.5 \mathrm{mN} \mathrm{m}^{-1}\right)$. As a result, both technical grade glycerol and the matter organic non-glycerin fraction had lower contact angles than distilled glycerol. The examined physical properties of distilled glycerol were found to be very close to that of the commercially available pure glycerol. The results suggest that technical grade glycerol may have potential application in the production of glycerol/fuel blends or biosurfactants. The presented results indicate that surface tension measurements are more useful when examining the quality of biofuel wastes than is density determination, as they allow for a more accurate analysis of the effects of impurities on the physical properties of the biofuel by-products.
\end{abstract}

Keyw ords: rapeseed biofuel, waste, surface tension, glycerol

\section{INTRODUCTION}

One of the problems of the biofuels industry is the formation of a number of by-products. Crude glycerol is the primary by-product, accounting for about $10 \mathrm{wt} \%$ of the biodiesel product (Johnson and Taconi, 2007; Zhang and
$\mathrm{Wu}, 2015)$. It is classified as a waste in some countries and should be stored in barrels and disposed of in landfills (Saifuddin et al., 2014). It consists mostly of a fraction called "matter organic non-glycerin" (MONG, up to $50 \%$ ), glycerol (over 30\%), water (over 10\%) and other impurities (Saifuddin et al., 2014). These impurities and their content vary according to the type of oil and catalysis process used in the biofuel production. The MONG is generated by the contamination of soap, methanol and methyl esters in the glycerol residue from the biodiesel production process (Kongjao et al., 2010). The crude glycerol obtained from the recovery process undergoes refining processes where impurities are removed (Ardi et al., 2015). The refining processes separate glycerol into the following generally accepted grades: partially purified and distilled pure. Partially purified glycerol (purity of ca. 92\%) is a technical grade glycerol. It can be used as the main carbon source for biosurfactant production (de Suosa et al. 2014) or as an ingredient for animal feed (Yang et al., 2012). The other use of technical grade glycerol is as an additive for gasoline and diesel fuels (Johnson et al., 2016) or as a heating agent (Mize et al., 2013). Furthermore, some attempts have been made to use technical grade glycerol as a plasticiser for the production of biodegradable films (Nobrega et al., 2012; Bilck et al., 2015). Distilled glycerol (over $99 \%$ pure) is mainly used for technical applications or in household chemicals. It is used as a substrate for chemical 
synthesis in food, pharmaceuticals, or cosmetics industries (Johnson and Taconi, 2007). To date, there is no literature on the use of the MONG fraction after its removal form crude glycerol.

Technological processes require the delivery of semifinished products with strictly defined properties and parameters. Therefore, in order to find the use of all organic waste fractions from the production of biofuels, it is necessary to determine their physicochemical properties. In the previous work, three independent optical methods (UV-Vis spectroscopy, infrared spectroscopy and chromametric measurements) were applied to establish a possible quality control test for the wastes from the conversion of rapeseed oil to biofuel (Sujak et al., 2014). UV-Vis and infrared spectroscopy can give rapid information about the purity of by-products, while the measurements of chroma can give the quickest information to compare the colour of samples obtained by different producers. The subsequent work determined the rheological properties, including the viscosity and activation energies of biofuel wastes from rapeseed oil (Muszyński et al., 2016a). The influence of the waste type on its dynamic viscosity was demonstrated and the MONG fraction was characterised by the highest dynamic viscosity. What is more, the lowest content of impurities was found in distilled glycerol, and its rheological properties were similar to those determined for commercial glycerol and the observed differences in the activation energies were thought to result from the different molecular organisation of their molecules and different water content (Muszyński et al., 2016a).

This paper provides an approach aimed at examining other properties of wastes from the conversion of rapeseed oil to biofuel with regard to their applicability in industry. We conducted a systematic study of the wetting behaviour and determination of the surface tension of distilled glycerol, technical grade glycerol and the MONG fraction to expand the existing knowledge about their physicochemical properties. We believe such measurements will be helpful in finding the possible applications of biofuel wastes or the preferred methods of their purification.

\section{MATERIALS AND METHODS}

The analysed wastes from rapeseed oil biofuel production (distilled glycerol, technical grade glycerol and the MONG fraction) were part of a batch of biofuel produced in the Rafineria Trzebinia S.A. refinery (presently Orlen Południe S.A., Poland). The samples were stored in opaque, 5-litre air-tight barrels. Analytical grade commercial glycerol with a purity of $99.5 \%$ (Avantor-POCH Gliwice, Poland) was used as an external reference.

Measurements of the density of the samples were performed with the AccuPyc 1330 helium gas pycnometer (Micromeritics, Inc., Norcross, GA, USA) equipped with a $10 \mathrm{~cm}^{3}$ stainless steel measuring cylinder. Before analysis, $2 / 3$ of the cylinder was filled with the sample, the weight was recorded and specified in analysis mode. All measurements were performed at a temperature of $20^{\circ} \mathrm{C}$, with five repetitions. The parameters of the measurement cycle were as described previously (Sołowiej et al., 2015).

The study of the surface tension of the samples was carried out at $20^{\circ} \mathrm{C}$, using the pendant drop method with a Theta Lite tensiometer (Attension/Bioline Scientific, Espoo, Finland) (Tomczyńska-Mleko et al., 2014). Each liquid sample was subjected to eight measurements. The images were recorded and analysed using OneAttension Software (Attension/Bioline Scientific, Espoo, Finland).

The same apparatus and software were employed for contact angle measurements using the sessile drop technique (Muszyński et al., 2016a; 2016b). A drop of the examined liquid was placed on the surface of the selected material via a $1 \mathrm{ml}$ syringe equipped with Type $3\left(90^{\circ}\right)$ stainlesssteel chromatographic needle with an internal diameter of $0.51 \mathrm{~mm}$ (Hamilton Co., Reno, USA). The readings of contact angles for each drop were taken $20 \mathrm{~s}$ after the formation of the drop. The mean value of the contact angle measured on both sides of the droplet was taken as a result of the measurement (Muszyński et al., 2017b). The presented data are the mean of eight independent determinations at different sites of each surface type. The selected test surfaces were stainless steel, Teflon (polytetrafluoroethylene, PTFE), glass and acrylic glass (polymethylmethacrylate, PMMA). For samples tested on the glass surface, the recordings were taken at the intervals of $2 \mathrm{~s}$ for the period of first $24 \mathrm{~s}$ after drop formation.

All results are expressed as means. The differences between the means were tested with one-way ANOVA and the post hoc Tukey's HSD test. Normal distribution of data was examined using the Shapiro-Wilk W-test, and equality of variance was tested by the Brown-Forsythe test. A P value of less than 0.05 was considered statistically significant. All statistical analyses were carried out by means of Statistica 12 PL software (StatSoft Polska Sp. z o. o., Kraków, Poland).

\section{RESULTS AND DISCUSSION}

The densities of technical grade glycerol $\left(1.300 \mathrm{~g} \mathrm{~cm}^{-3}\right)$ and distilled glycerol $\left(1.267 \mathrm{~g} \mathrm{~cm}^{-3}\right)$ did not differ statistically from the density of commercial glycerol $(1.265 \mathrm{~g}$ $\mathrm{cm}^{-3}$ ), as highlighted in Fig. 1a. The determined values of density are in good agreement with the values from the other source, where the density of commercial glycerol and technical grade glycerol (containing $1.5 \%$ of water and over $93 \%$ of glycerol) were determined as 1.267 and $1.250 \mathrm{~g}$ $\mathrm{cm}^{-3}$, respectively (Kongjao et al., 2010). The density of the MONG fraction was $1.579 \mathrm{~g} \mathrm{~cm}^{-3}$ (Fig. 1a).

The comparison of the surface tension of the tested biofuel wastes is presented in Fig. 1b, while Fig. 2 shows example images of the measurement of the surface ten- 
a
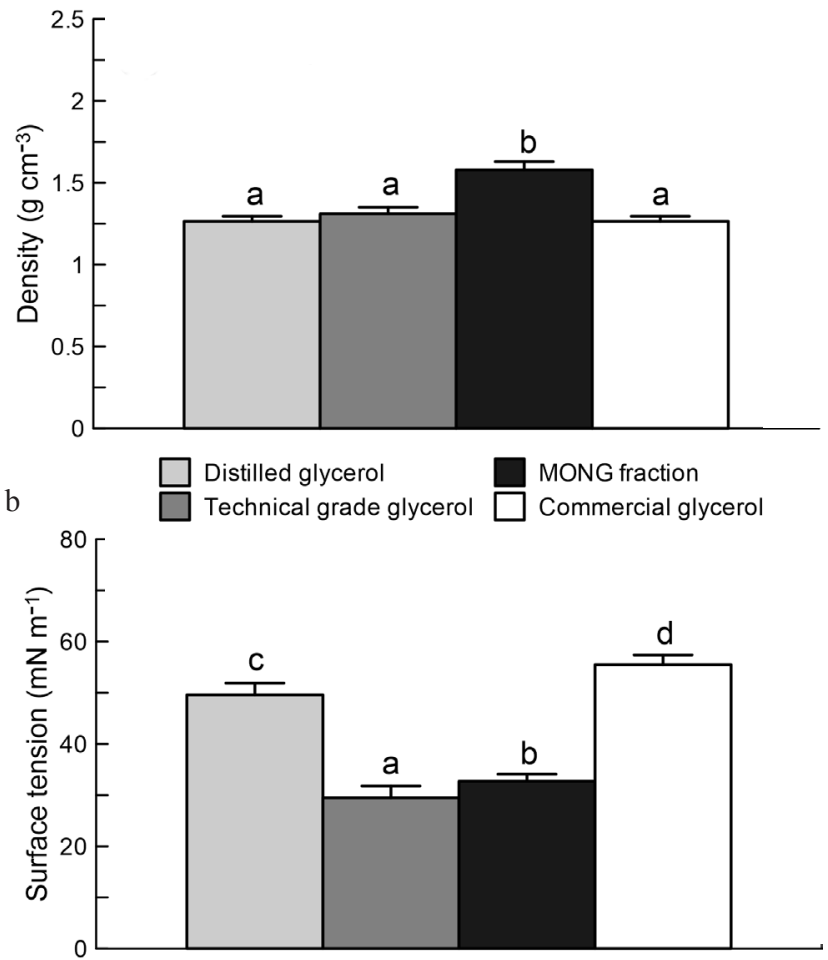

Fig. 1. Densities (a) and surface tensions (b) of the tested biofuel by-products (distilled glycerol, technical grade glycerol and the MONG fraction) and commercial glycerol. The measurements were performed at a temperature of $20^{\circ} \mathrm{C}$. Data are presented as mean and corresponding standard deviation. The different letters denote statistically significant differences between the tested samples $(\mathrm{p}<0.05)$.

sion with the pendant drop method. The highest surface tension was observed for commercial glycerol $(55.5 \mathrm{mN}$ $\left.\mathrm{m}^{-1}\right)$, followed by distilled glycerol $\left(49.6 \mathrm{mN} \mathrm{m}^{-1}\right)$, the MONG fraction $\left(32.7 \mathrm{mN} \mathrm{m}^{-1}\right)$ and technical grade glycerol $\left(29.5 \mathrm{mN} \mathrm{m}^{-1}\right)$. Statistical analysis revealed differences between all groups.

The lower values of the surface tension of glycerols obtained from biofuels wastes are most probably associated with the presence of impurities. Surface tension arises from the unbalance of the force between the molecules of the liquid. This includes intermolecular forces due to permanent and induced dipoles and hydrogen bonding, and instantane-

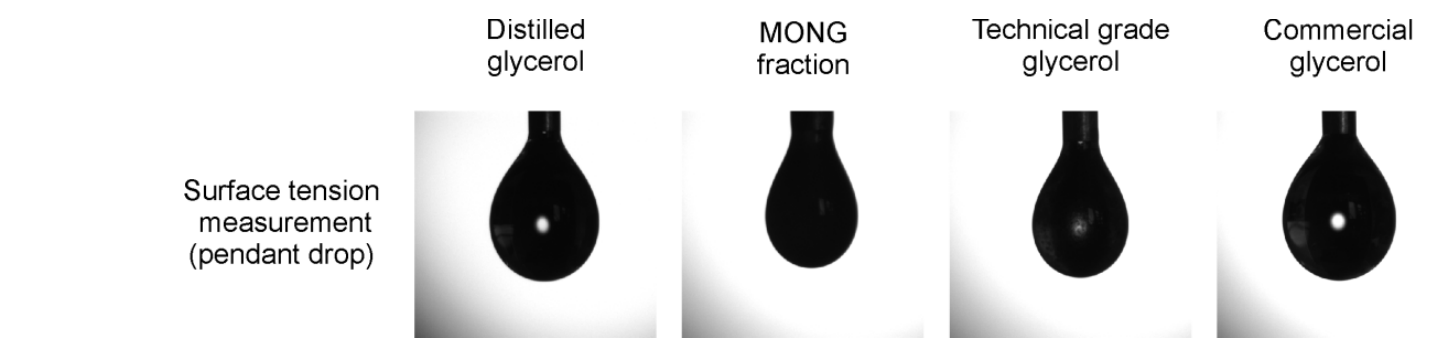

ous dipole moments, like the Coulomb interaction between two molecules. Waste glycerols from biodiesel production usually contain methanol, soap, catalysts, salts, MONG and water (Hansen, et al., 2009; Posada and Cardona, 2010). For example, the MONG content in commercial glycerol is $<0.001 \%$; in technical grade glycerol $<6 \%$ and in distilled glycerol $<1.5 \%$ (Kongjao et al., 2010; Saifuddin et al., 2014).

One potential use of glycerol could be as a liquid fuel in industrial furnaces. It was recently reported that blending glycerol with bio-oil or diesel fuel seems to be a promising approach for producing a liquid fuel mixture with fuel physical properties suitable for stationary combustion application without major furnace or burner modifications (Mize et al., 2013; Zhang and Wu, 2015). Blending glycerol into bio-oil or diesel fuel by emulsification of glycerol and glycerol/diesel emulsions was successfully achieved employing commonly available surfactants (Eaton et al., 2014). However, it is important to understand how glycerol impurities influence the stability of the glycerol/fuel system, as the surfactant requirements for emulsifying glycerol into oil or diesel depend on the levels of impurities, especially water, ash and MONG (Mize et al., 2013). The key physical properties of this fuel blend include viscosity, surface tension and density (Zhang and Wu, 2015). As it was shown, distilled glycerol had relatively high surface tension ( $c a .50 .0 \mathrm{mN} \mathrm{m}^{-1}$ ), which was two times greater than that of diesel $\left(23.5 \mathrm{mN} \mathrm{m}^{-1}\right)$. This higher surface tension requires increased fuel rail pressure (Eaton et $a l ., 2014)$. The surface tension of glycerol/diesel blend is about $32 \mathrm{mN} \mathrm{m}^{-1}$ at a glycerol content of $5 \%$ (Arruda et al., 2015). If the impurities present in technical grade glycerol can be tolerated in the production of fuel blends, technical grade glycerol could be directly used for fuel blending (Zhang and $\mathrm{Wu}, 2015$ ). In that case, the purification process for technical grade glycerol may be simplified. Moreover, technical grade glycerol is characterised by a lower surface tension, which is beneficial as reduced glycerol/fuel interfacial tension is desirable and limits the required surfactant concentrations (Eaton et al., 2014).

Glycerol as a by-product of varying purity is also highly applicable as an alternative substrate for the production of biosurfactants (de Sousa et al., 2014; Salazar-Bryam et

Fig. 2. The recorded images of the surface tension measurements, using the pendant drop method, of the tested biofuel by-products (distilled glycerol, technical grade glycerol, the MONG fraction) and commercial glycerol. 
al., 2017). Again, the examined technical glycerol had low surface tension - which is desirable in the production of biosurfactants using bio-wastes (Bharali et al., 2014).

Finally, surface tension plays an essential role in the efficiency with which by-products are separated from biodiesel. One of the methods of biodiesel purification is liquid/liquid separation (Anez-Lingerfelt, 2014). The most important factors in this type of purification are interfacial tension, viscosity, density and temperature. Two liquid phases can be separated easily if the interfacial tension between them and the difference in density are high (Anez-Lingerfelt, 2014). The density and surface tension of rapeseed biofuel are $882 \mathrm{~g} \mathrm{~cm}^{-3}$ and $32.2 \mathrm{mN} \mathrm{m}^{-1}$, respectively (Freitas et al., 2011). The determined values of density and the surface tension of the MONG fraction are $1.579 \mathrm{~g} \mathrm{~cm}^{-3}$ and 32.7 $\mathrm{mN} \mathrm{m}^{-1}$, respectively. This indicates that efficient separation of the MONG fraction will be possible mainly due to the differences in densities.

The contact angle was measured to compare the wetting behaviour of the tested biofuel wastes on different surfaces. The example images of the layout of the experiment as drops formed by tested liquids on selected surfaces are shown in Fig. 3. A low contact angle indicates greater wettability of the liquid and vice versa. The value of the contact angle results from both the surface tension of the liquid and the surface free energy of solid material. The latter controls adhesion, adsorption, wettability and similar surface-related properties (Muszyński et al., 2016b; 2017a). To our knowledge, measurements of contacts angles have not been ever performed for any bio-fuel wastes, including glycerols of different purity and the MONG fraction.

Distilled glycerol obtained from biofuel production wastes and commercial analytical grade glycerol showed no significant differences in the values of contact angle on the examined surfaces, indicating that these liquids have similar wetting properties (Fig. 3). The only statistically significant difference was observed on the Teflon (PTFE) surface (108.2 and $97.6^{\circ}$, for distilled glycerol and commercial glycerol, respectively, Fig. 4). Both technical grade glycerol and the MONG fraction had lower contact angles than distilled glycerol and commercial glycerol, indicating a difference in the wetting properties. More surprisingly, no statistical differences were observed between technical grade glycerol and the MONG fraction (Fig. 4).

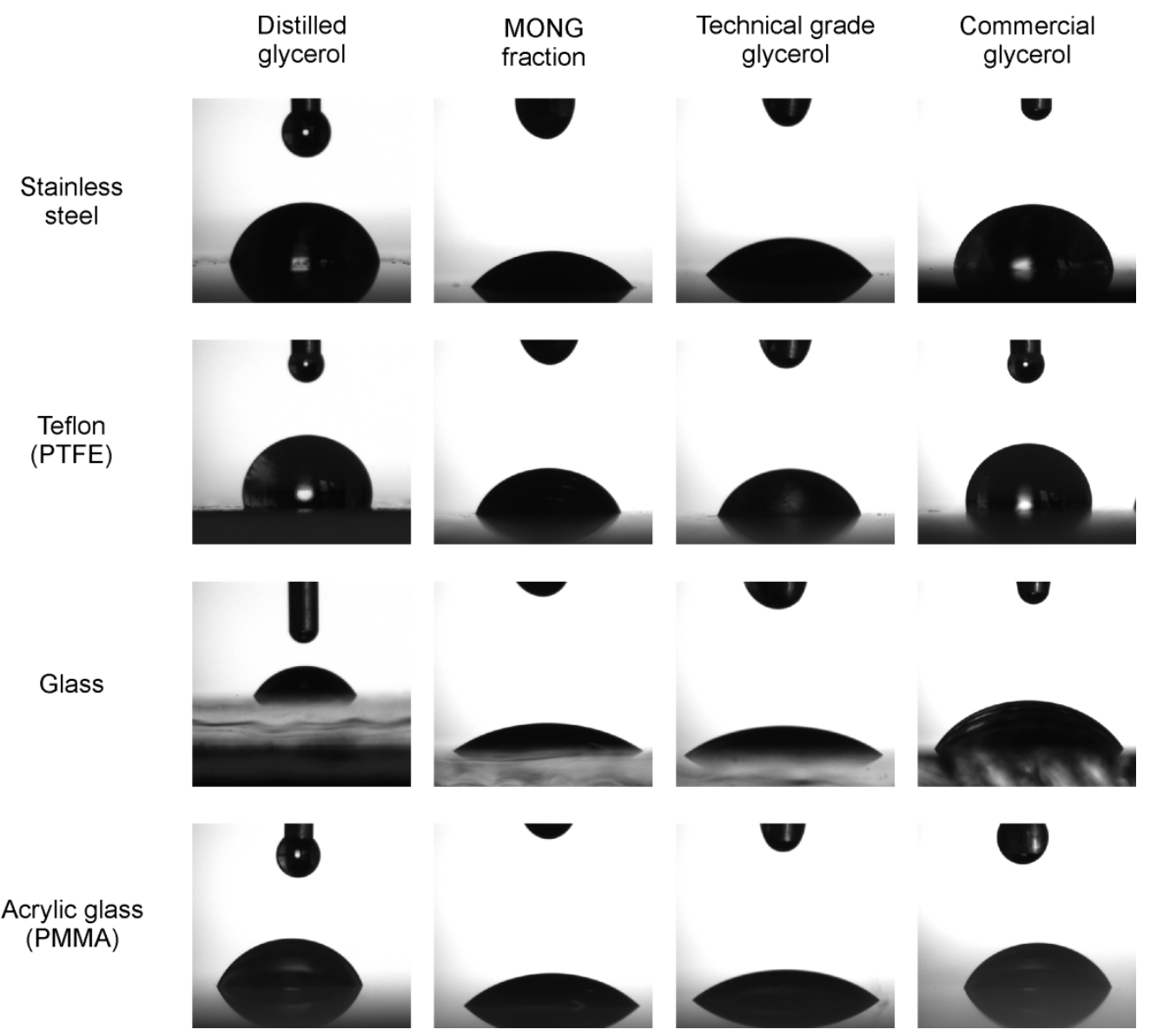

Fig. 3. Measurements of the wetting behaviour of the tested biofuel by-products (distilled glycerol, technical grade glycerol, the MONG fraction) and commercial glycerol on: stainless steel, Teflon (polytetrafluoroethylene, PTFE), glass, acrylic glass (polymethylmethacrylate, PMMA). 

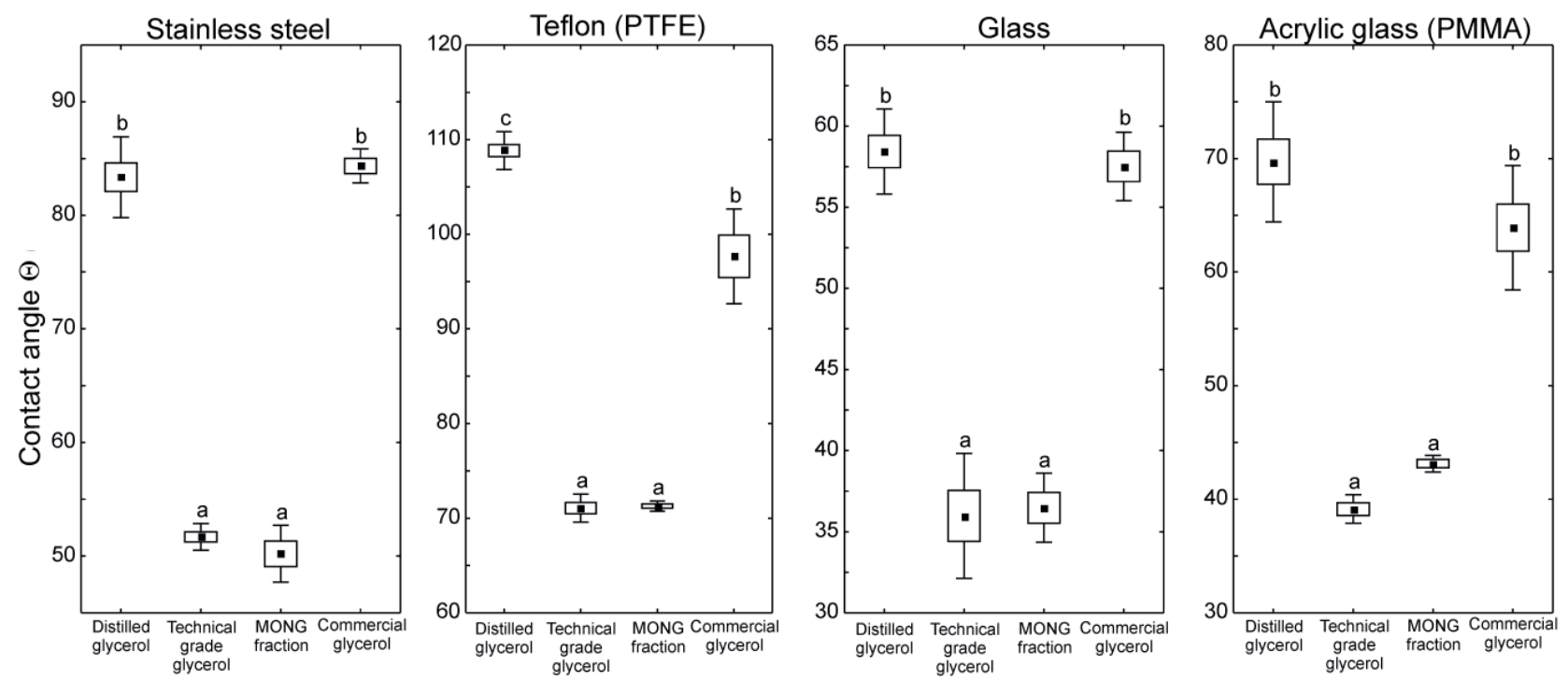

Fig. 4. Contact angles $\left(^{\circ}\right)$ of tested biofuel by-products (distilled glycerol, technical grade glycerol and the MONG fraction) and commercial glycerol on different surfaces. From left: stainless steel, Teflon (polytetrafluoroethylene, PTFE), glass, acrylic glass (polymethylmethacrylate, PMMA). The point denotes the mean value, the box indicates the standard error and the whiskers indicate the standard deviation. The different letters denote statistically significant differences between the tested samples $(p<0.05)$.

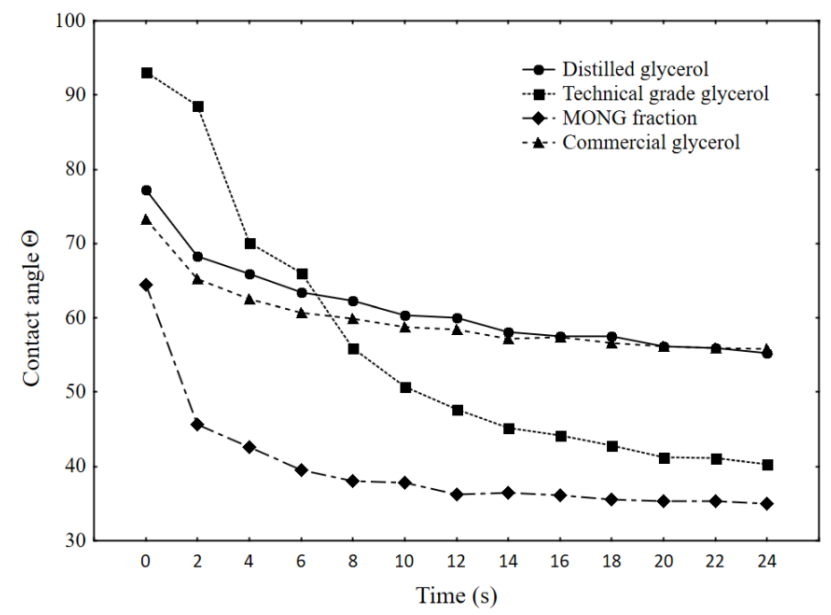

Fig. 5. The kinetics of water drop contact angle $\left(^{\circ}\right)$ changes for tested biofuel wastes (distilled glycerol, technical grade glycerol and the MONG fraction) and commercial glycerol - on a glass surface.

The observed differences in the wetting behaviour between the analysed samples are attributable most probably to the different values of surface tension. This behaviour could also be associated with glycerol composition, as technical grade glycerol had approximately 10\% less glycerol than distilled glycerol ( $c a .91$ and over 99\%, respectively) and contains a number of impurities. For both technical glycerol and the MONG fraction, increased wetting characteristic can also be associated with the hydrogen bonds between glycerol's hydroxyl groups and the water molecules present in the liquids (Müller et al., 2008). Figure 5 shows the kinetics of the water drop contact angle of tested biofuel wastes and commercial glycerol on the surface of glass. The figure reveals similarity in the spreading of distilled glycerol and commercial glycerol. It can be also concluded that technical grade glycerol is characterised by the least stable wetting behaviour, exhibiting the greatest changes in the contact angle.

As mentioned above, no data was found in the general literature search concerning the usage of the MONG fraction. However, there have been attempts to employ crude glycerol in the spray application of herbicide (Arruda et al., 2015). As technical grade glycerol also contains a MONG fraction, the surface tension and wettability of both the MONG fractions and technical grade glycerol can be essential for attempts at similar applications. For example, low surface tension might increase the tendency of the solution to leak out and might increase the risk of foaming in the system, and of cavitation in the pump.

\section{CONCLUSIONS}

1. Technical grade glycerol was characterised by a low surface tension. This is desirable in the production of glycerol/fuel blends or for the production of biosurfactants.

2. We obtained distilled glycerol from biofuel waste that was acceptably compliant with commercially available analytical grade glycerol.

3. The surface tension analyses are more accurate and useful at examining the quality of biofuel wastes than are density measurements, as they allow for a better determination of the effects of impurities on the physicochemical properties of the examined samples. 
4. Contact-angle measurement is the most informative and reliable technique to physically describe the wetting behaviour of liquids.

Conflict of interest: The Authors do not declare conflict of interest.

\section{REFERENCES}

Anez-Lingerfelt M., 2014. High efficiency coalescers for liquid/ liquid separation applications in biodiesel production and use. American Filtration and Separations Society Spring, Conf. Oil and Gas and Chemical Filtration and Separations. March 24-26, Cincinnati, OH, USA.

Ardi M.S., Aroua M.K., and Awanis Hashim N., 2015. Progress, prospect and challenges in glycerol purification process: A review. Renew. Sust. Energ. Rev., 42, 1164-1173.

Arruda R.L., do Vale Nunes M., da Silva P.R., Leão F.F., de Almeida Sarmento R., Nunes T.V., and Erasmo E.A.L., 2014. Glycerine associated molecules with herbicide for controlling Adenocalymma peregrinum in cultivated pastures. Afr. J. Biotechnol. 14, 3075-3081.

Bharali P., Singh S.P., Dutta N., Gogoi S.,. Bora L.C, Debnath P., and Konwar K., 2014. Biodiesel derived waste glycerol as an economic substrate for biosurfactant production using indigenous Pseudomonas aeruginosa. RSC Adv., 4, 38689-38706.

Bilck A.P., Müller C.M.O., Olivato J.B., Mali S., Grossman M.V.E., and Yamashita F., 2015. Using glycerol produced from biodiesel as a plasticiser in extruded biodegradable films. Polímeros, 25, 331-335.

de Sousa M., Dantas I.T., Felix A.K.N., de Sant'Ana H.B., Melo V.M.M., and Goncalves L.R.B., 2014. Crude glycerol from biodiesel industry as substrate for biosurfactant production by Bacillus subtilis ATCC 6633. Braz. Arch. Biol. Technol., 57, 295-301.

Eaton S.J., Harakas G.N., Kimball R.W., Smith J.A., Pilot K.A., Kuflik M.T., and Bullard J.M., 2014. Formulation and combustion of glycerol-diesel fuel emulsions. Energy Fuels, 28, 3940-3947.

Freitas S.V.D., Oliviera M.B., Queimada A.J., Pratas M.J., Lima A.S., and Coutinho A.P., 2011. Measurement and prediction of biodiesel surface tensions. Energy Fuels, 25, 4811-4817.

Hansen C.F., Hernandez A., Mullan B.P., Moore K., TrezonaMurray M., King R.H., and Pluske J.R., 2009. A chemical analysis of samples of crude glycerol from the production of biodiesel in Australia, and the effects of feeding crude glycerol to growing-finishing pigs on performance, plasma metabolites and meat quality at slaughter. Anim. Prod. Sci., 49, 154-161.

Johnson D.T. and Taconi K.A., 2007. The glycerin glut: options for the value-added conversion of crude glycerol resulting from biodiesel production. Environ. Prog., 26, 338-346.

Johnson E., Sarchami T., Kießlich S., Munch G., and Rehmann L., 2016. Consolidating biofuel platforms through the fermentative bioconversion of crude glycerol to butanol. World J. Microbiol. Biotechnol., 32, 103.

Kongjao S., Damronglerd S., and Hunsom M., 2010. Purification of crude glycerol derived from waste used-oil methyl ester plant. Korean J. Chem. Eng., 27, 944-949.
Mize H.E., Lucio A.J., Fhaner C.J., Pratama F.S., Robbins L.A., and Karpovich D.S., 2013. Emulsions of crude glycerin from biodiesel processing with fuel oil for industrial heating. J. Agric. Food Chem., 61, 1319-1327.

Muszyński S., Sujak A., Budzeń M., Tomczyk A., Mleko S., and Tomczyńska-Mleko M., 2016a. Rheological properties of wastes from conversion of rapeseed oil to biofuel. Przem. Chem., 95, 2245-2248.

Muszyński S., Kwaśniewska A., Mleko S., Tomczyńska-Mleko M., and Gladyszewska B., 2016b. Wollastonite-filled and arabic gum-modified starch films. Part 2. Adhesion properties. Przem. Chem., 95, 2242-2244.

Muszyński S., Kwaśniewska A., Sołowiej B., Tomczyk A., Leus A., Szymanek M., Siedliska K., and Gladyszewska B., 2017a. Physical properties of kaolin clay-containing pectin gels. Przem. Chem., 96, 422-426.

Muszyński S., Kwaśniewska A., Oniszczuk T., Szymanek M., Tomczyk A., Leus A., and Gladyszewska B., 2017b. Aging of biodegradable thermoplastic starch film under UV-irradiation. Przem. Chem., 96, 891-893.

Müller C.M.O., Yamashita F., and Laurindo J.B., 2008. Evaluation of the effects of glycerol and sorbitol concentration and water activity on the water barrier properties of cassava starch films through a solubility approach. Carbohyd. Polym., 72, 82-87.

Nobrega M.M., Olivato J.B., Bilck A.P., Grossmann M.V.E., and Yamashita F., 2012. Glycerol with different purity grades derived from biodiesel: Effect on the mechanical and viscoelastic properties of biodegradable strands and films. Mater. Sci. Eng. C, 32, 2220-2222.

Posada J.A. and Cardona C.A., 2010. Design and analysis of fuel ethanol production from raw glycerol. Energy, 35, 5286-5293.

Saifuddin N., Refal H., and Kumaran P., 2014. Rapid purification of glycerol by-product from biodiesel production through combined process of microwave assisted acidification and adsorption via chitosan immobilized with yeast. Res. J. Appl. Sci. Eng. Technol., 7, 593-602.

Salazar-Bryam A.M., Barros Lovaglio R., and Contiero J., 2017. Biodiesel byproduct bioconversion to rhamnolipids: Upstream aspects. Heliyon, 3, e00337.

Sołowiej B., Glibowski P., Muszyński S., Wydrych J., Gawron A., and Jeliński T., 2015. The effect of fat replacement by inulin on the physicochemical properties and microstructure of acid casein processed cheese analogues with added whey protein polymers. Food Hydrocoll., 44, 1-11.

Sujak A., Muszyński S., and Kachel-Jakubowska M., 2014. Quality of rapeseed bio-fuel waste: optical properties. Int. Agrophys., 28, 213-218.

Tomczyńska-Mleko M., Kamysz E., Sikorska E., Puchalski C., Mleko S., Ozimek L., Kowaluk G., Gustaw W., and Wesołowska-Trojanowska M., 2014. Changes of secondary structure and surface tension of whey protein isolate dispersions upon ph and temperature. Czech J. Food Sci., $32,82-89$.

Yang F., Hanna M.A., and Sun R., 2012. Value-added uses for crude glycerol-a byproduct of biodiesel production. Biotechnol. Biofuels, 5, 13.

Zhang M. and Wu H., 2015. Effect of major impurities in crude glycerol on solubility and properties of glycerol/methanol/ bio-oil blends. Fuel, 159, 118-127. 